\title{
Probiotics industry: review of current challenges and the future roadmap
}

\author{
Behzad Damari $^{1}$, Maryam Tajabadi Ebrahimi ${ }^{2}$, Elnaz Jafarvand ${ }^{3 *}$ \\ 1. Neuroscience Institute, Tehran University of Medical Sciences, Tehran, Iran \\ 2. Central Tehran Branch, Islamic Azad University, Tehran, Iran \\ 3. School of Nutritional Sciences and Dietetics, Tehran University of Medical Sciences, Tehran, Iran
}

Received: 8 January 2021

Accepted for publication: 23 June 2021

[EPub a head of print-3 July 2021]

Payesh: 2021; 20 (3): 263-273

\begin{abstract}
Objective (s): Deaths from non-communicable diseases have become a major concern worldwide. Functional foods such as probiotics, prebiotics and synbiotics are effective nutritional factors in controlling non-communicable diseases. The purpose of this study was to review and organize the existing situation and design the future roadmap.

Methods: The present study was a qualitative study that conducted by the Society of Probiotic and Functional Foods in collaboration with the National Institute of Health Research of the Islamic Republic of Iran in 2015. The policy brief was used in design and was formulated in three parts: cognition, orientation, and establishment of system. The information was collected through three methods of scientific resource review, stakeholder focus group discussion and written questionnaire. Data were analyzed using content analysis method.

Results: The number of probiotic factories was 85 and 163 probiotic products had received production licenses in the country. The annual growth of the probiotic market from 2009 to 2014 was negative (54\%). The policy focus areas for the development of probiotics and functional foods were distributed in three areas: legal policy, behavioral culture and operational structure and the development of this industry depends on planning and implementation in all three areas.

Conclusion: To develop the probiotic industry it is necessary to increase the knowledge of policy makers and consumer groups about probiotic products. Indeed, investment security in this area be provided and a system be deployed to monitor the development of the industry and solve its problems.
\end{abstract}

Key Words: Probiotics, Prebiotics, Policy Brief, Focus Group Discussion

\footnotetext{
* Corresponding author: School of Nutritional Sciences and Dietetics, Tehran University of Medical Sciences, Tehran, Iran

E-mail: Elnazjafarvand@yahoo.com
} 


\title{
توسعه صنعت يروبيوتيك: بررسى جالش هاى كنونى و ارايه نقشه راه آينده
}

\author{
بهزاد دمارى'، مريم تاج آبادى ابراهيمى`، الناز جعفروند" \\ ا. يزروهشكده علوم اعصاب، دانشكاه علوم بزشكى و خدمات بهداشتى درمانى تهران، تهران، ايران

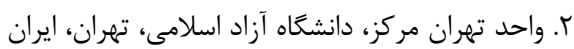

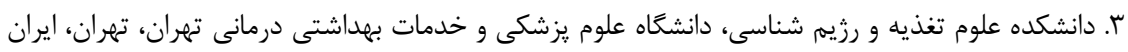

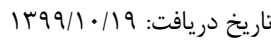

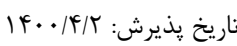

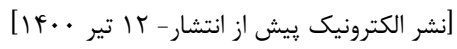

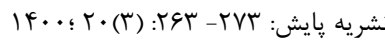

جكيده

مقدمه: مرگ و مير ناشى از بيمارى هاى غير واگير به يك نخرانى عمده در سراسر جهان تبديل شده است. از عوامل تغذيه اي موثر در كنترل اين بيمـارى

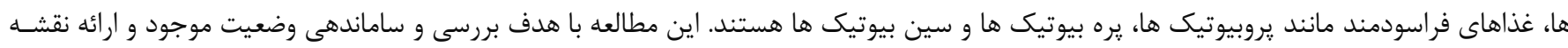

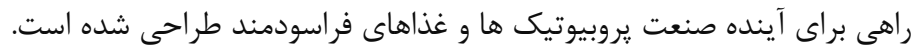

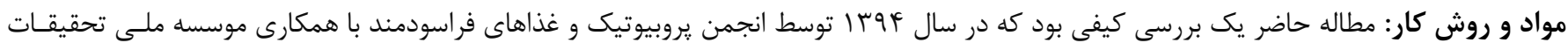

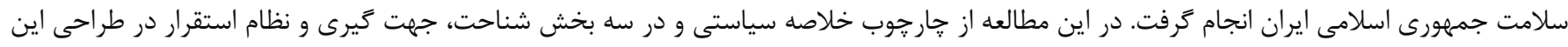

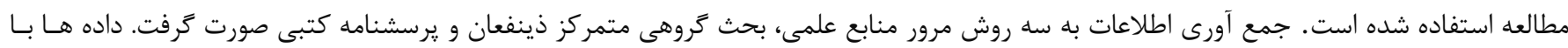
استفاده از روش تحليل محتوا تحليل گرديد.

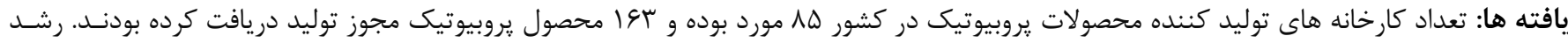

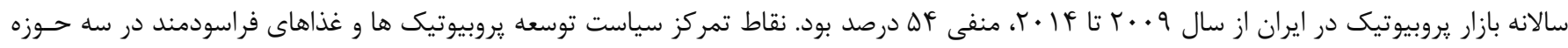

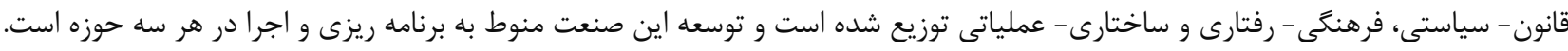

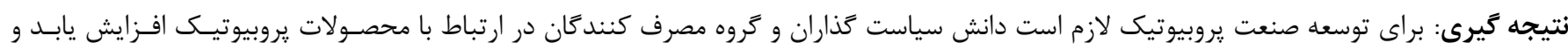

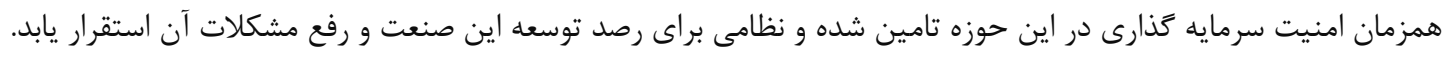
كليدوازه: يروبيوتيك، يره بيوتيك، خلاصه سياستى، بحث گروهى متمركز 
طريـق افـزايش احسـاس سـيرى، بِيشـخيرى از سـرطان و تنظـيمم

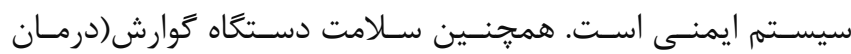

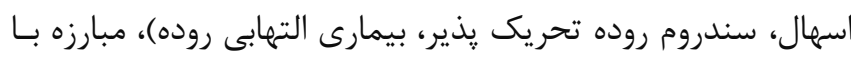

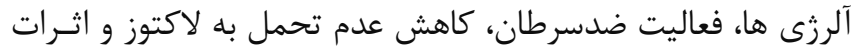

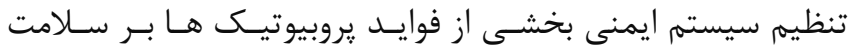

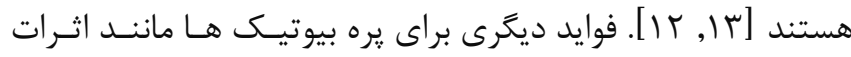

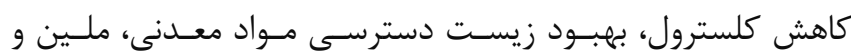
تنظيم دفع مطرح است. يروبيوتيك ها نيز نقش مثبت در جلوكيرى

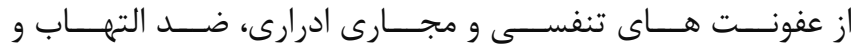

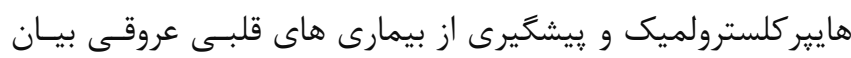

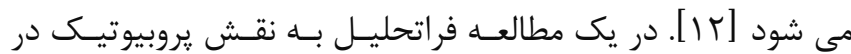

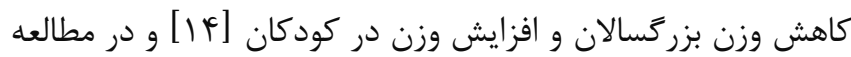

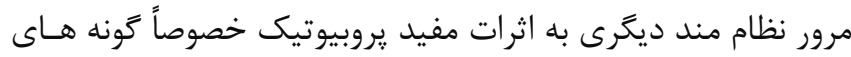
لاكتوباسيلوس در كنترل :ارامترهاى خونى مرتبط بــا ديابـت اشـاره

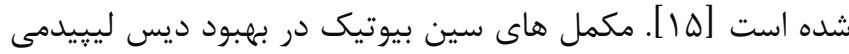

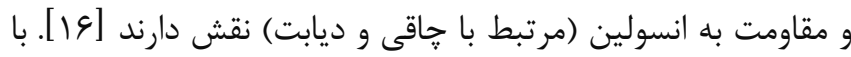

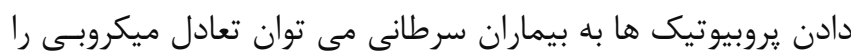

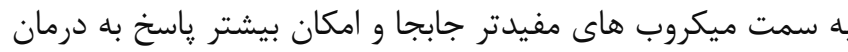

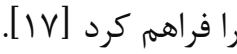

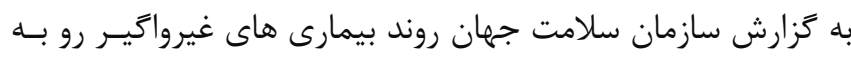

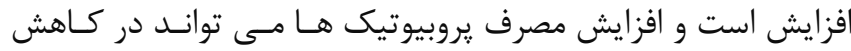
اين بيمارى ها و توسعه קٍايدار كشورها موثر باشـد، امـا متاسـفانه در

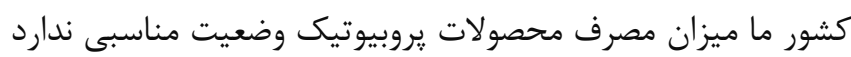

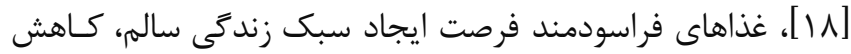

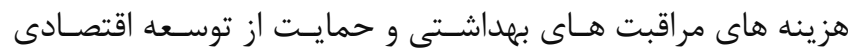

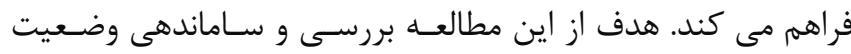

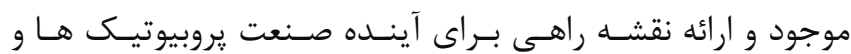
غذاهاى فراسودمند در كشور است.

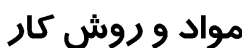

در اين مطالعه از خارجوب طراحى خلاصه سياستى استفاده شد كه شامل سه بخش است: 1- بخش شناخت با هدف توصيف وضعيت كمى و كيفى صـنـعت و و

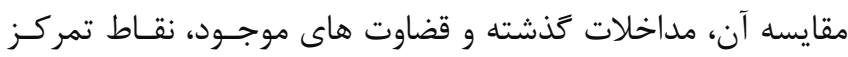

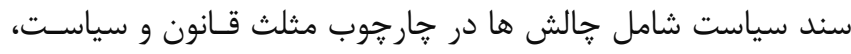
ساختار و عمليات، رفتار و فرهنَ صـورت كرفـت. جمـع آورى داده

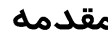

مركى و مير ناشى از بيمارى هاى مزمن توسط برنامــه اقـدام جهـانى

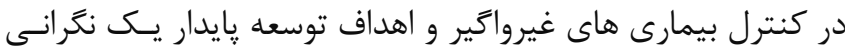

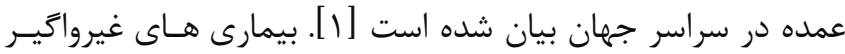
مهمترين علت مرك و مير زودرس و ناتوانى در سطح جهان هستند

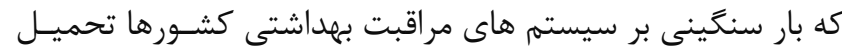

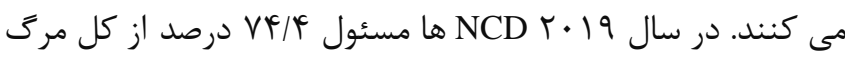

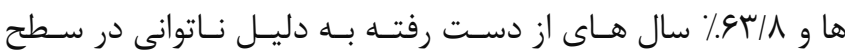
جهانى بودند [r]. تخمين زده مى شود كه • •1 درصد از كل مركى و

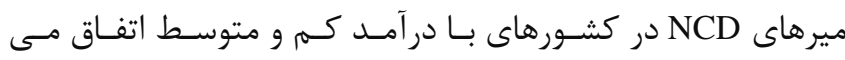

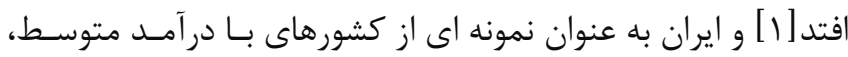

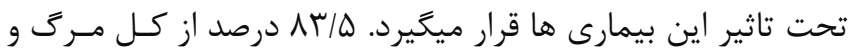

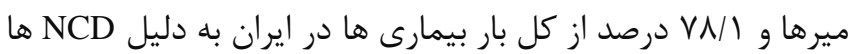

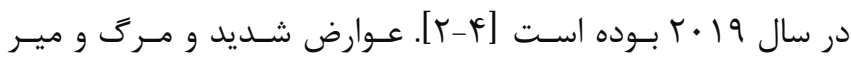
زودرس بيمارى هاى غير واگير باعث مى شود كه اين مســئله مـورد توجه سياست كذاران قرار كيرد.

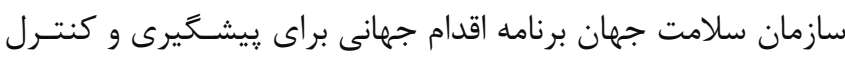
NCDs كه شامل مصرف دخانيات، رزيم ناسالم، عدم فعاليت بدنى و مصـرف

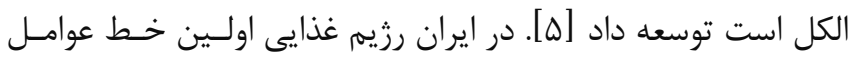

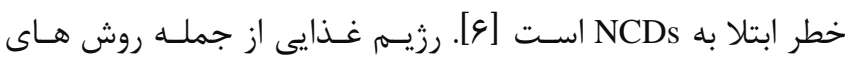

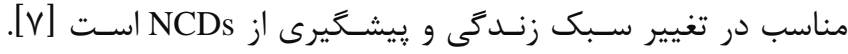
رزيم غذايى نقش مهمى در تعديل تركيب ميكروبى روده دارد و يك ديك

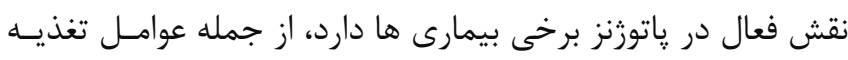

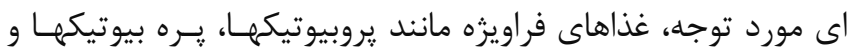

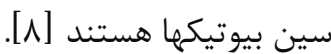

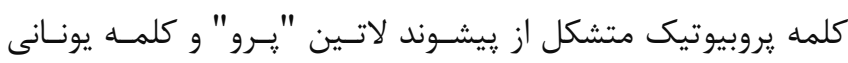

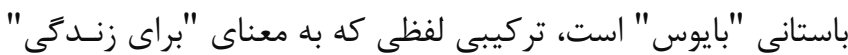

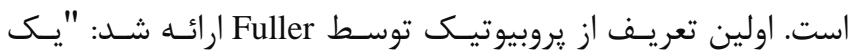
مكمل خوراكى ميكروبى زنده كه اثرات سودمندى بر بهبـود تعـادل

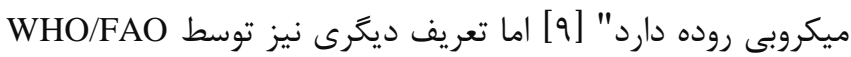

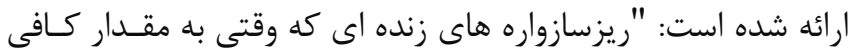

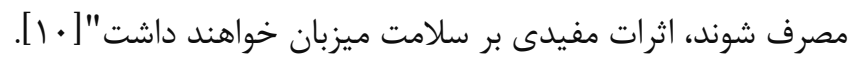

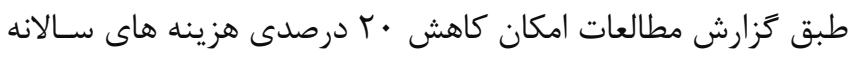

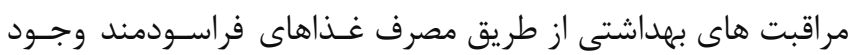

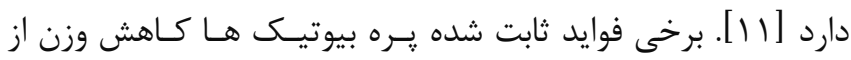


نشريه يروهشكده علوم بهداشتى جهادانشگاهى

راهبردى صورت گرفت كه با استفاده از مـرور منـابع بخـش اول بــه دست آمدند. r- بخش الزامات استقرار كه با هدف استقرار سند يروبيوتيك كشور صورت گرفت شامل تـامين شـواهد، توانمنـــى نيروهـاى انسـانى و جُخونكى ساختار اجرايى، تامين مالى برنامه بود كه با توجه به نتـايج دو بخش قبلى توسط اعضاى فنى تدوين گرديد.

هافته ها

فراورده هاى غـذايى فراسـودمند و يروبيوتيـك موجـود در جهـان و ايران شامل محصولات لبنى (ماست، دوغ، بستنى و ينير)، نوشيدنى

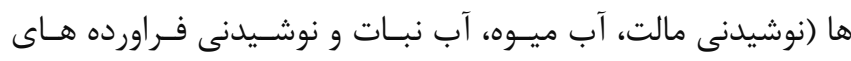

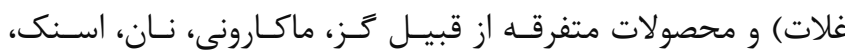
شكلات خوراك دام و يفك) است.

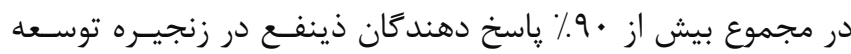

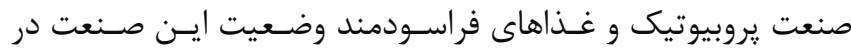

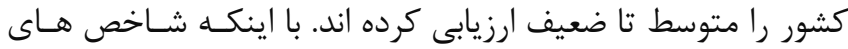
معتبرى براى مقايسه ايـن صـنعت در ايسران و جهــان در دسـترس

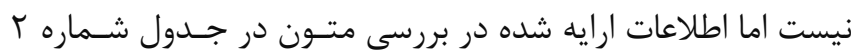
آمده است. رايج ترين روش رساندن :بروبيوتيك ها محصولات لبنسى مانند شير، ماست و كفير هستند كه مى تواند ريشه تاريخى داشـته روسي

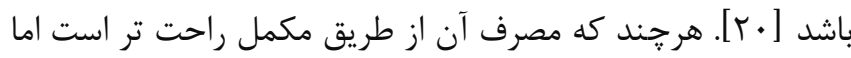

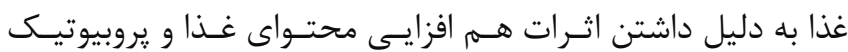

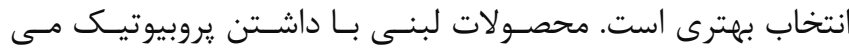
توانند ريزمغذى هاى با كيفيت بالا شامل كلسيه، يروتئين، يِّيدها،

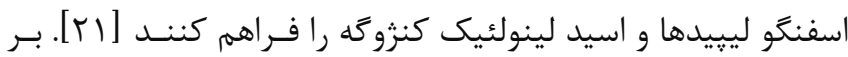
اساس زَارش مميزى توسعه علوم در اين حوزه كه توسـط معاونـت علمى رياست جمهورى منتشر شده است در حال حاضـر در تمـامى

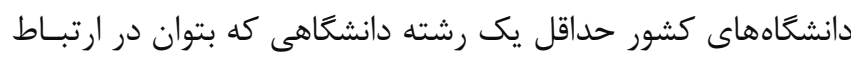

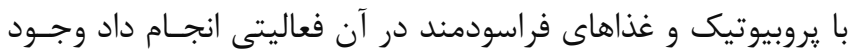

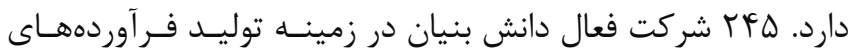

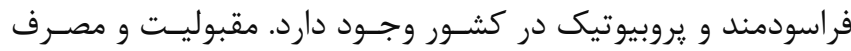

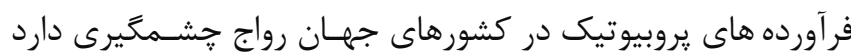

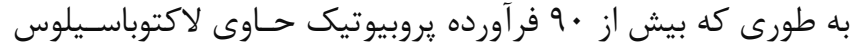
سيدوفيلوس در سرتاسر جهان توليد مى شود. بــر اسـاس اطلاعـات

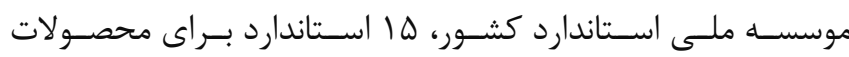

با استفاده از مرور متون، يرسشنامه كتبى و بحث گروهى متمركز به دست آمد. مرور منابع توسط يك فرد آشنا به علـم تغذيـهـ و صـنايع

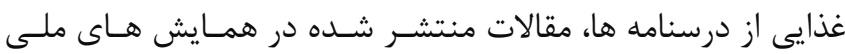

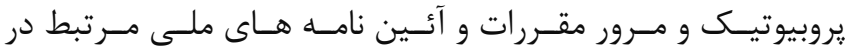
يايخاههاى اينترنتى سازمان ملى استاندارد (فهرسـت اسـتانداردهاى

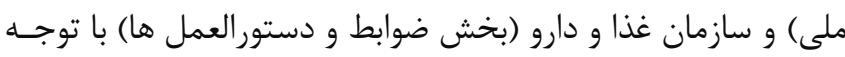

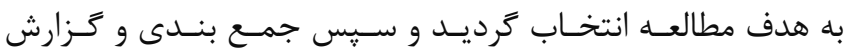

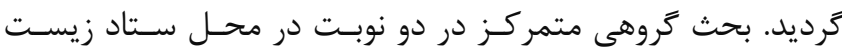

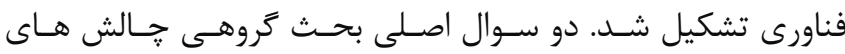

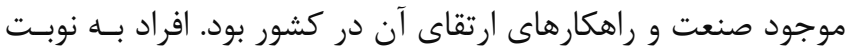
نظرات خود را ارايه كردند و يـس از دو مرحلـه سـوالات و ابهامـات براى ياسخكَويى شركت كنندگان از طرف تسهيل گر جلسه مطـرح شد. صورت جلسات بحث گروهى متمر كز به متن تبديل و در نهايت به روش تحليل كيفى تحليل شد. تحليل ذينفعان بر اساس دو مولفه تعهد و اثر صورت گرفتـ. بـدين

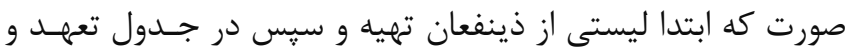

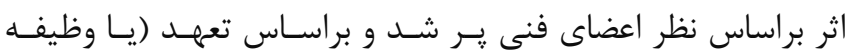
قانونى) و اثر در ســه سـطح بـالا و متوسـط و يـايين وزن داده شـد

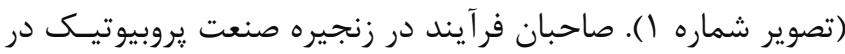
جهار زروه قرار گرفتند: 1 - صنعت بستر ساز (وارد كننده ها و توليد كنند لبنى و غيرلبنى، مرغ، گاو و گوسفند و آبزيان، توليـد خــوراك دام و

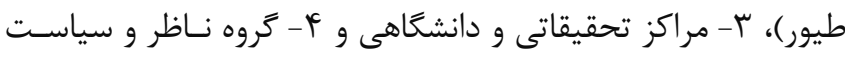

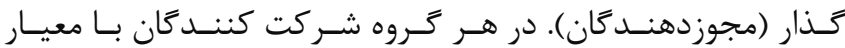
علاقمندى به همكارى و صرف وقت در جلسـات انتخــاب شـدند. در مجموع سץ نفر در جلسات بحث گروهى متمركـز و تكميـل كنـــده

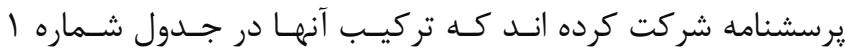
ززارش شده است. همجنين يرسشنامه شامل دو سوال اصـلى توصـيف وضـعيت حـال حاضر صنعت يروبيوتيك بود كه پيس از پاسخكويى ذينفعان تحليـل شد. يرسشنامه در ابتداى جلسه بحث زروهـى و يسـ از توضـيحات محققان توزيع و تكميـل شـدند. شـركت كنـــــان همـان اعضـاى

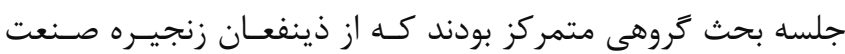
يروبيوتيك و غذاهاى فراسودمند انتخاب شده بودند.

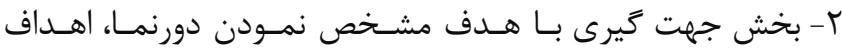
راهبردى مورد انتظار، مداخلات قابل اجرا براى دستيابى بــه اهــداف 
زير درون مايههاى مرتبط با جالش هاى توسعه صنعت يروبيوتيك و

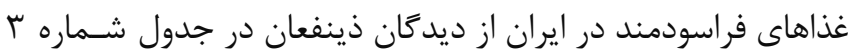

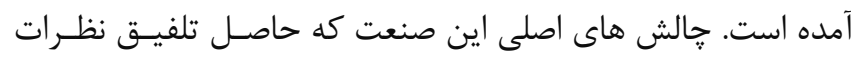
ذينفعان و تحقيقات انجام شده در كشـور اسـت در سـه درون مايسهـ

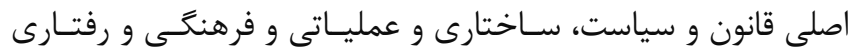

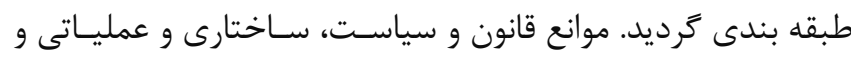

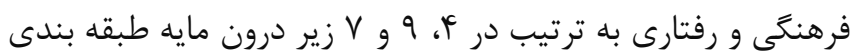

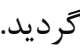

يكى از زير درون مايه هاى مرتبط با موانع قانونى و سياستى، نبودن

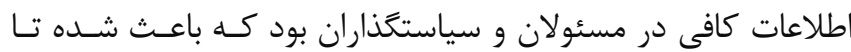

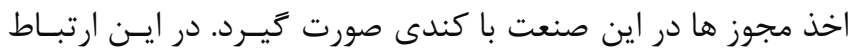
يكى از مشاركت كنند

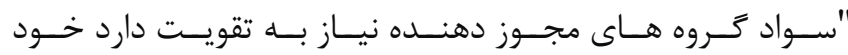

مجوزدهندكان از ارزش اين مواد آكاه نيستند."

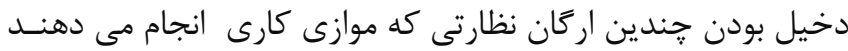

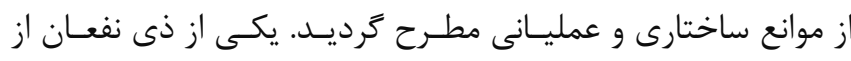

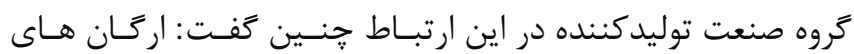
نظارتى بيشتر از مجريان در كشور حضور دارند: سـازمان اسـتاندارد،

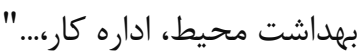

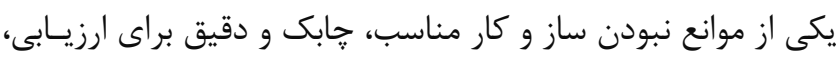

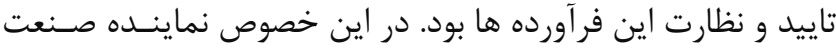

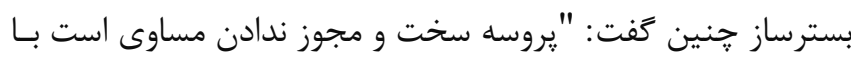

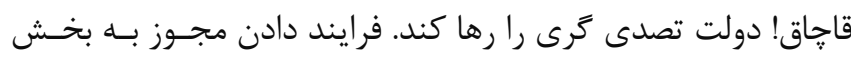

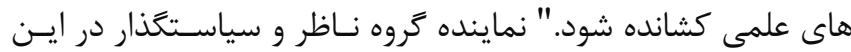

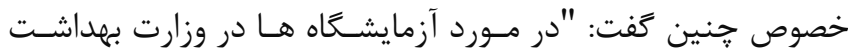

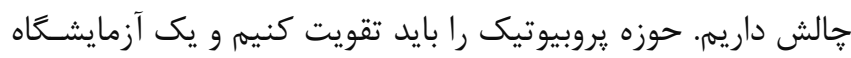

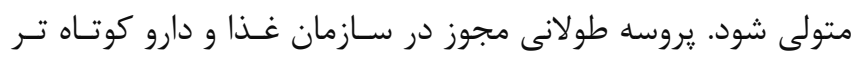

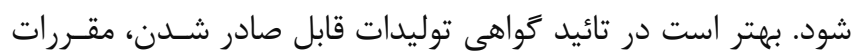

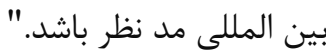

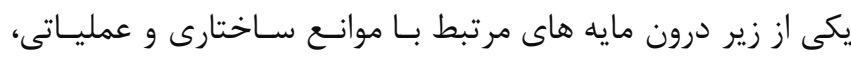

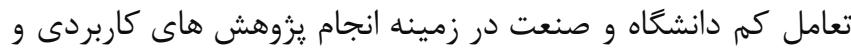

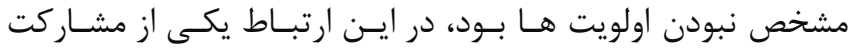

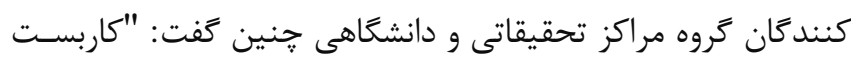

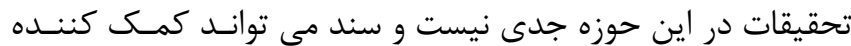

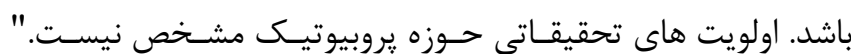
نماينده صنعت توليـد كنـــده در ايسن خصـوص جنـــين بيـان كـرد:
يروبيوتيك در كشور تدوين شده بود و سه اسـتاندارد ديخـــ نيـز در

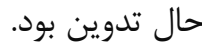
به طور كلى اطلاعات به دسـت آمــده از مقـالات و مطالعـات داخـل

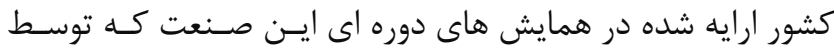

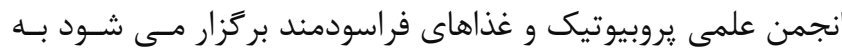

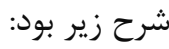

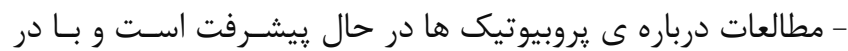

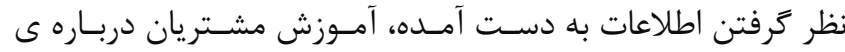

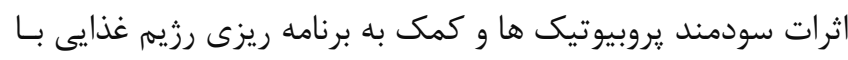

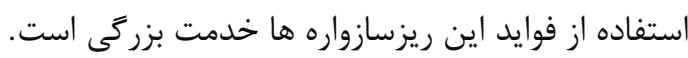

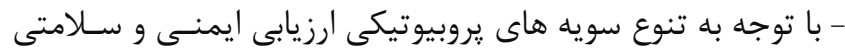
توسط متخصصين و افراد ذيصلاح بسيار ضرورى است.

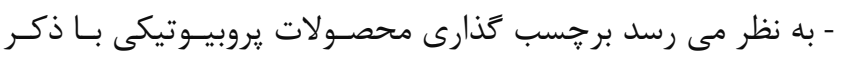
نوع و تعداد ريزسازواره هاى موجود ضرورى باشد.

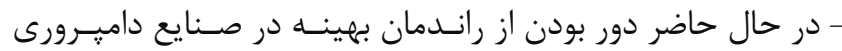

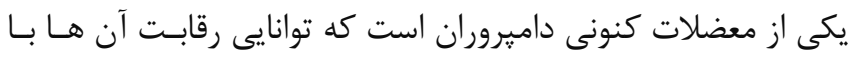
بازارهاى جهانى را تضعيف نموده است.

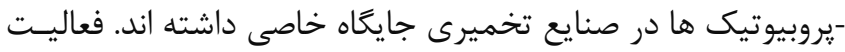

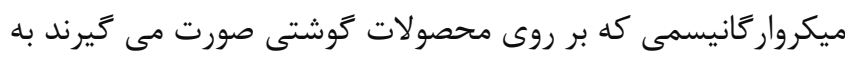

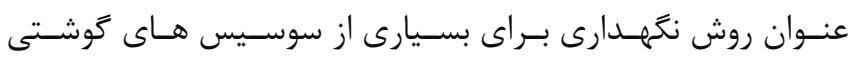

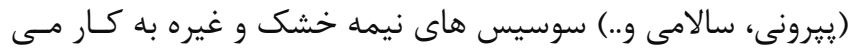

- يكى از جالش هاى غذاهاى توليد شده با استفاده از زيست فنـاورى

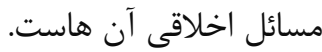
-استفاده از محصولات يروبيوتيك مى تواند در بهببود ضريب تبـديل

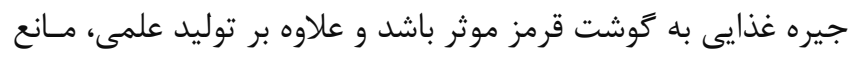

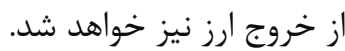

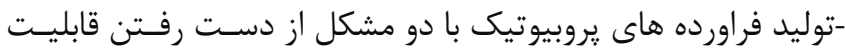
زيستى يروبيوتيك ها و احتمال رضايت بخش نبودن خواص حسى نيى محصول نهايى همراه است. -يكى از جالشهاى بزرى بيشرفت فناورى در همهى كشورها، ايجاد

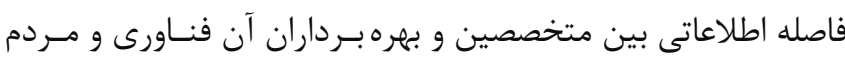

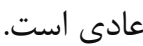
در جلسه دوم بحث كروهى متمركز تقريبا كزاره هاى مشابه جلسـهـ

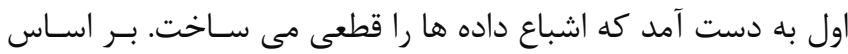

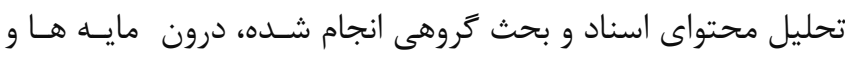


نشريه يثروهشده علوم بهداشتى جهاددانشگاهى

فراهم مى كند. اجراى دو مداخله شامل برنامـهـ بازاريـابى اجتمـاعى

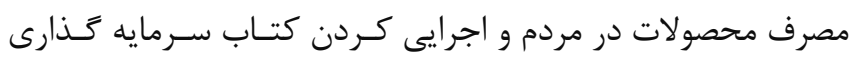

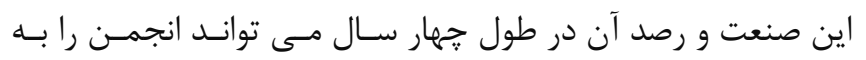
دورنماى تعيين شده برساند. بخش الزامات استقرار كه با هدف اسـتقرار ســند يروبيوتيـك كشـور

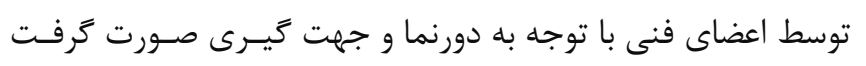

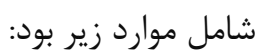

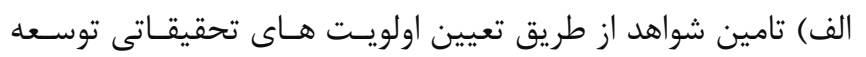

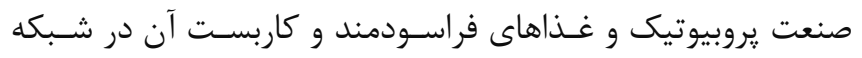

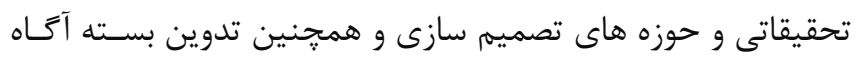

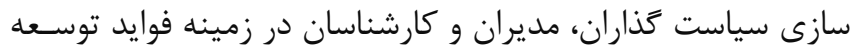

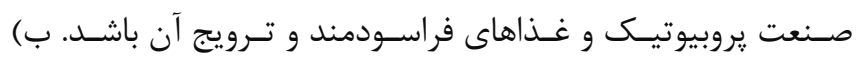

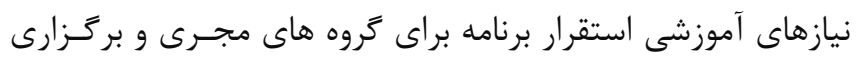

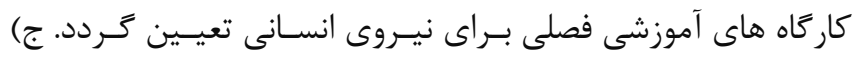

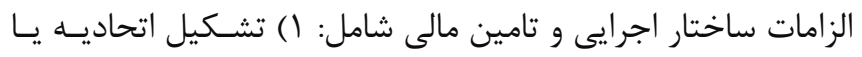

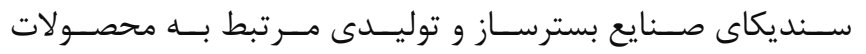

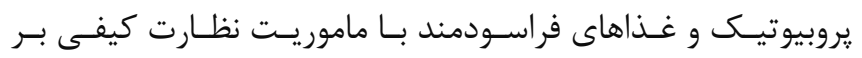

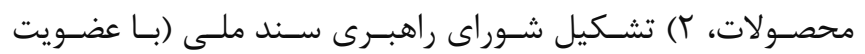

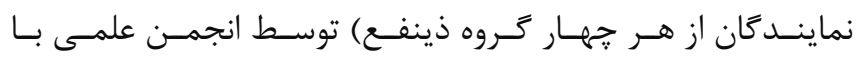

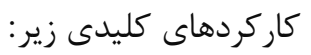

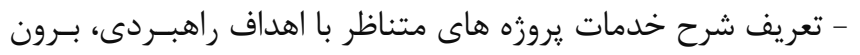
سيارى و كاربست نتايج يروزه ها

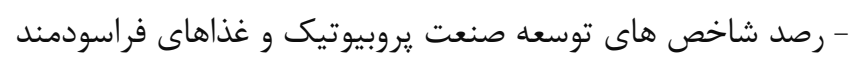
و ارايه ززارش سالانه مربوطه

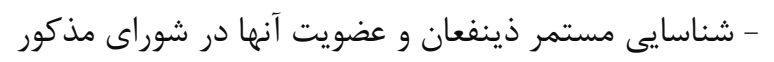

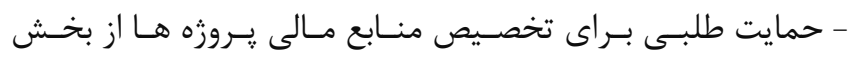
خصوصى و كمك هاى دولتى نـى تخصي

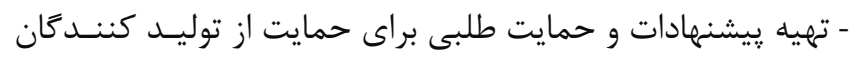

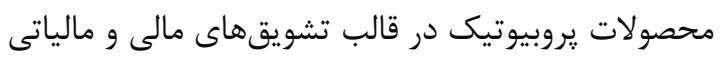

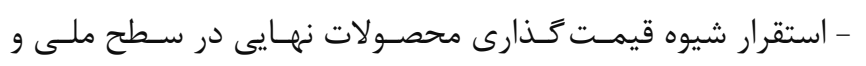

منطقه اى - بركزارى سمينار ها و همايش هاى تخصصى با مشـاركت صـنعت و دانشخاه

- اطلاع رسانى مستمر فعاليت ها و نتايج يروزه ها

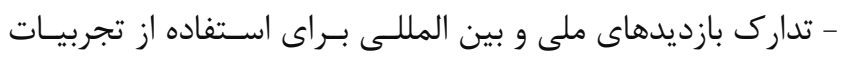
متقابل
"ارتباط بين صنعت و دانشكاه ضعيف اسـت و همــاهنكى در زمينــهـ

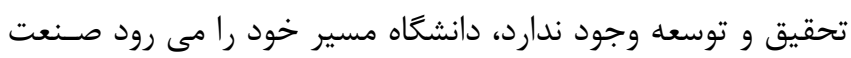

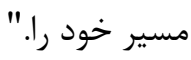

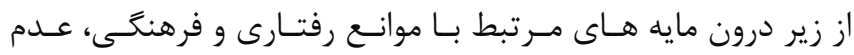

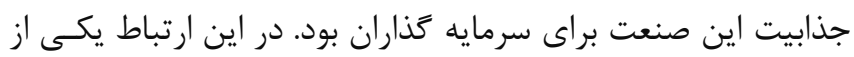

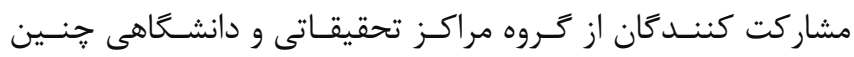

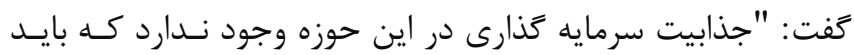

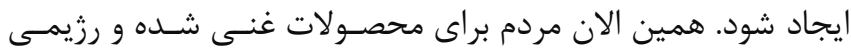

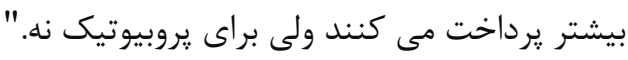

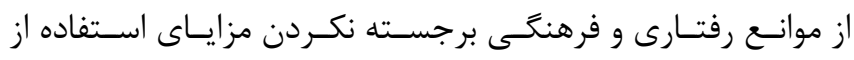

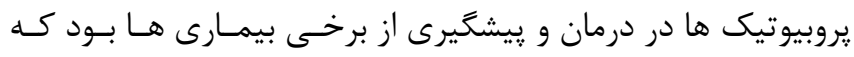

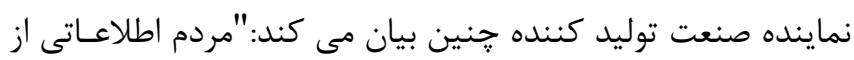

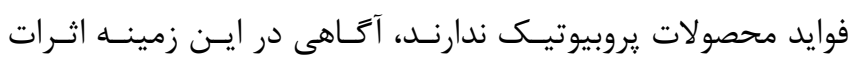

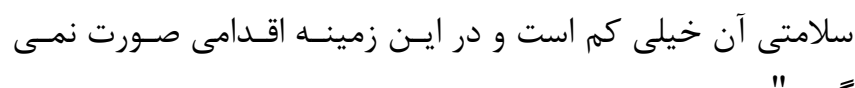

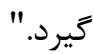
توسعه اين صنعت منوط به برنامه ريزى و اجرا در سه حوزه قـانونى في فئس

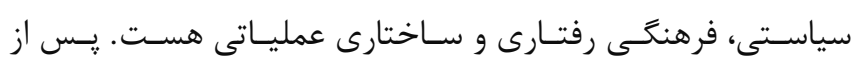

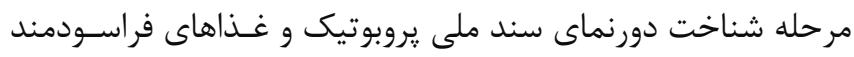

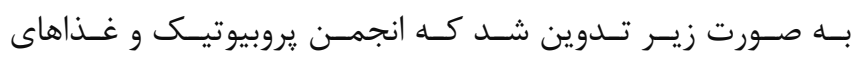

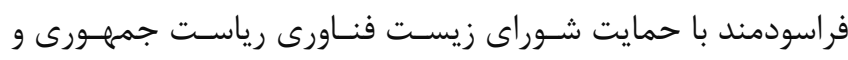

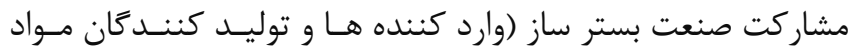

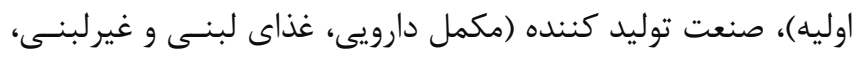

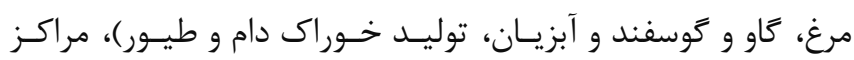

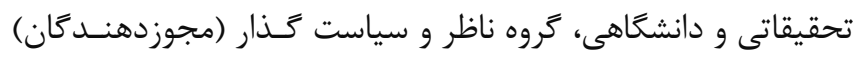

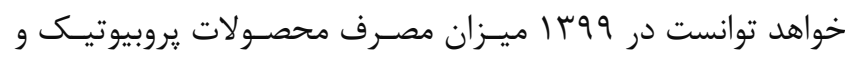

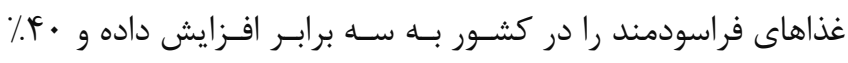

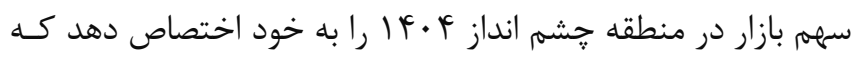

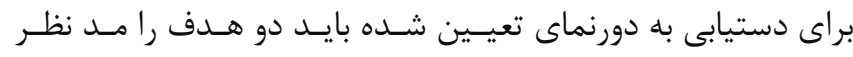

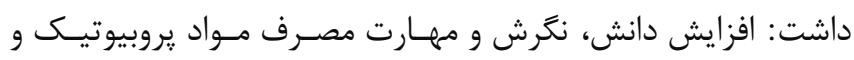

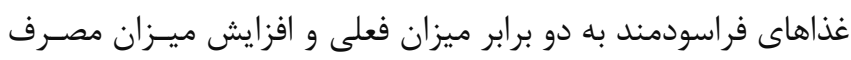
مواد يروبيوتيك و غذاهاى فراسودمند به دو برابر فعلى (در سال يايه

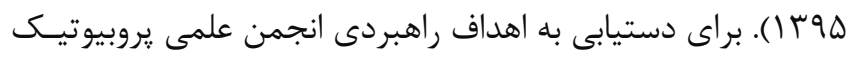

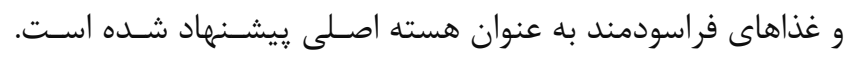

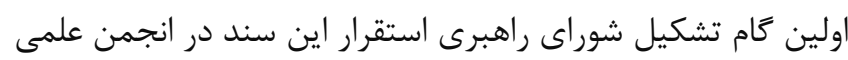

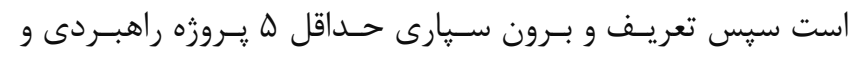

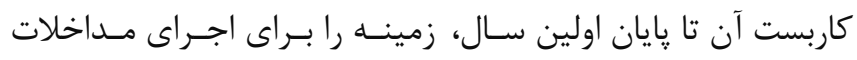


سال بيستم، شماره سوم، خرداد ـ تير ...

جدول ا: مشاركت كنندَان مطالعه در جلسات بحث كروهى متمركز و تكميل كننده يرسشنامه در بخش شناخت و جهت گيرى

\begin{tabular}{|c|c|}
\hline \multicolumn{2}{|l|}{ مشاركت كنندكًان } \\
\hline 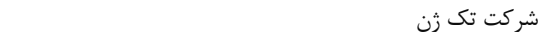 & 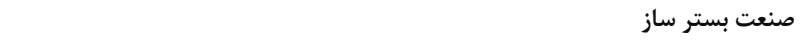 \\
\hline شركت نيكوتك وارد كننده & (وارد كننده ها و توليد كنندًان مواد اوليه) \\
\hline \multicolumn{2}{|l|}{ شركت فناورى كوشتى طبيعت كرا } \\
\hline \multicolumn{2}{|l|}{ 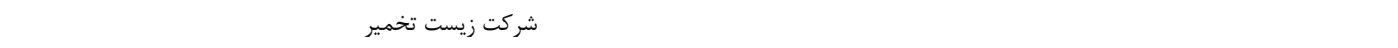 } \\
\hline \multicolumn{2}{|l|}{ شركت فن آورى زيستى طبيعت كرى } \\
\hline مدير توسعه شركت زرماكارون & صنعت توليد كننده \\
\hline مدير توسعه شركت تك ماكارون & (مكمل دارويى، غذاى لبنى و غيرلبنى، مرغ، كاو و كوسفند و آبزيان، توليد خوراك دام و طيور) \\
\hline \multicolumn{2}{|l|}{ مدير توسعه داليان مهر } \\
\hline \multicolumn{2}{|l|}{ 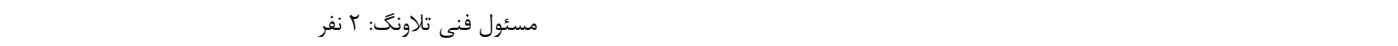 } \\
\hline \multicolumn{2}{|l|}{ انجمن مرغ كَوشتى كشور } \\
\hline \multicolumn{2}{|l|}{ شركت مينوى شرق (r نفر) } \\
\hline \multicolumn{2}{|l|}{ شركت دارو سازى تهران شيمى } \\
\hline \multicolumn{2}{|l|}{ محقق انستيتو تحقيقات تغذيه اى كشور } \\
\hline \multicolumn{2}{|l|}{ موسسه ملى تحقيقات سلامت } \\
\hline \multicolumn{2}{|l|}{ دانشكده تغذيه دانشكاه علوم يزشكى تهران } \\
\hline \multicolumn{2}{|l|}{ انجمن علمى } \\
\hline \multicolumn{2}{|l|}{ عضو هيات مديره انجمن علمى يروبيوتيك و ستاد زيست فناورى } \\
\hline \multicolumn{2}{|l|}{ عضو هيات مديره انجمن صنايع لبنى } \\
\hline \multicolumn{2}{|l|}{ 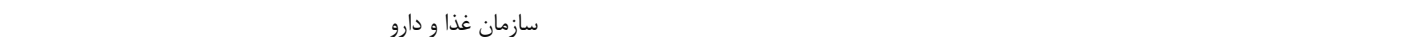 } \\
\hline \multicolumn{2}{|l|}{ دفتر بهبود تغذيه جامعه } \\
\hline \multicolumn{2}{|l|}{ 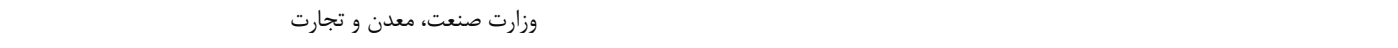 } \\
\hline سازمان داميزشكى & \\
\hline
\end{tabular}

جدول ז: توصيف وضعيت صنعت يروبيوتيك و غذاهاى فراسودمند در ايران و مقايسه با ساير كشورها وضعيت ايران در مقايسه با ساير كشورها شاخص تزارش شده

در ايران عدد دقيقى وجود ندارد ولى در جهان هفت بيليون دلار (آسيا و اقيانوسيه)

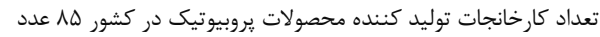
نصف قيمت محصول مشابه در خارج از كشور

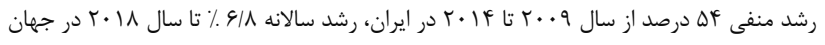
دريافت مجوز سعا محصول يروبيوتيك در كشور

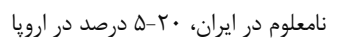

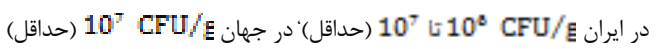

ميزان مصرف محصولات يروبيوتيك (دلار آمريكا)

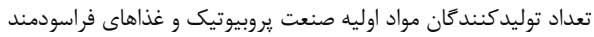

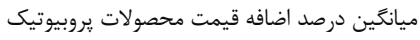

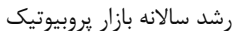

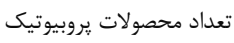
درصد سهمم ماست يروبيوتيك در بازار ميزان بروبيوتيك در محصولات لبنى (از زمان توليد تا انقضا) 
سال بيستم، شماره سوم، خرداد ـ تير If..

نشريه يروهشكده علوم بهداشتى جهاددانشكاهى

جدول بّ: حالش هاى توسعه صنعت بروبيوتيك و غذاهاى فراسودمند در ايران از ديدًان ذينفعان

\begin{tabular}{|c|c|c|}
\hline \multicolumn{2}{|c|}{ زير درون مايه } & \multirow{2}{*}{ نانون مايه اصلى } \\
\hline تمركز سياستكذاران بر كميت و در حاشيه قرار كرفتن بروبيوتيك ها كه مقوله كيفى است (عدم اولويت صنعت بروبيوتيك در كشور) & $(1$ & \\
\hline محدوديت هاى قيمتى براى توليدكنندكان فرآورده هاى يروبيوتيك از جانب مراجع نظارتى & $(r$ & \\
\hline محدوديت انجام تبليغات محصولات يروبيوتيك از طرف حوزه سلامت و بهداشت & $(r$ & \\
\hline نبودن اطلاعات كافى در مسئولين و سياستَذاران كه باعث شده تا اخذ مجوز ها در اين صنعت با كندى صورت كيرد & $\left(c^{c}\right.$ & \\
\hline افزايش قيمت تمام شده محصولات بروبيوتيك & $(1$ & ساختارى و عملياتى \\
\hline فقدان مديريت واحد در دولت در زمينه محصولات يروبيوتيك & $(r$ & \\
\hline نبودن ساز و كار مناسب، هابك و دقيق براى ارزيابى، تاييد و نظارت اين فرآورده ها & $(r$ & \\
\hline دخيل بودن קندين اركان نظارتى كه موازى كارى انجام مى دهند. & $(c$ & \\
\hline 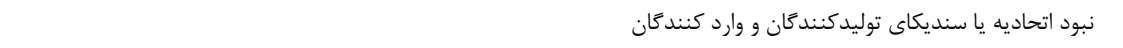 & $(\Delta$ & \\
\hline تعامل كم دانشًاه و صنعت در زمينه انجام يزوهش هاى كاربردى و مشخص نبودن اولويت ها & $(4$ & \\
\hline 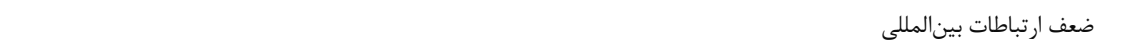 & $(\vee$ & \\
\hline ضعف آكاهى توزيع كنندكان و صنعتًران به يروسه زنجيره سرد & $(\wedge$ & \\
\hline 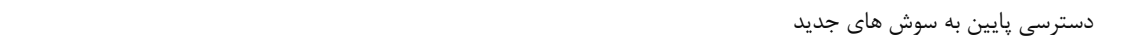 & $(9$ & \\
\hline جديد بودن صنعت توليد بروبيوتيك در كشور & $(1$ & رفتارى و فرهنكى \\
\hline عدم اثربخشى فورى اين فرآورده ها & $(r$ & \\
\hline شناخت ناكافى كارشناسان و متوليان صنعت غذا از عملكرد و تاثيرات محصولات يروبيوتيك و نداشتن اعتقاد كافى به آن & $(r$ & \\
\hline عدم جذابيت اين صنعت براى سرمايه كذاران & $(4$ & \\
\hline عدم اعتقاد مصرف كندكان و باور آنها به محصولات يروبيوتيك & $(\Delta$ & \\
\hline وجود بى تفاوتى در انتخاب يك نوع مواد غذايى يروبيوتيك و مواد غذايى مشابه & $(9$ & \\
\hline برجسته نكردن مزاياى استفاده از يروبيوتيك ها در درمان و ييشكَيرى از برخى بيمارى ها & $(\vee$ & \\
\hline
\end{tabular}

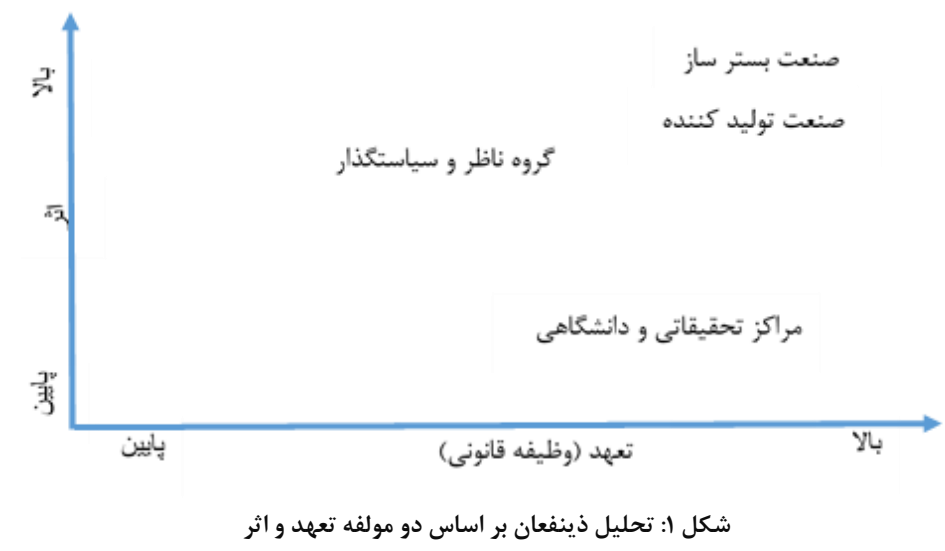

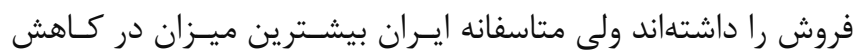
بحث و نتيجه گيرى فروش اين محصولات را به خـود اختصـاص داده اسـت. رونسد بــازار

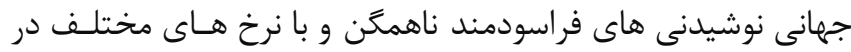
اين تحقيق با هدف بررسى و ساماندهى وضعيت موجود و ارائه نقشه راهى براى آينده صنعت يروبيوتيك ها و غذاهاى فراسـودمند انجـام حال رشد و توسعه است كه به نظر مى رسد به دليـل تفـاوت هـاى

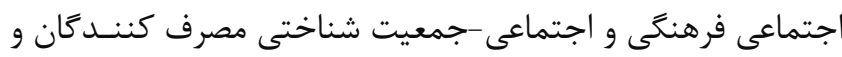

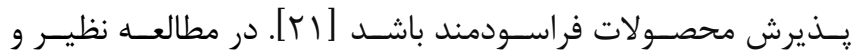
همكاران [آT]، تزارش شد كه توسعه محصولات غذايى قراسـودمند

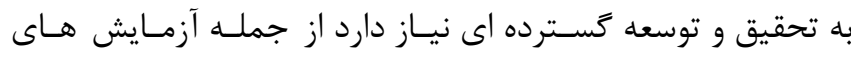

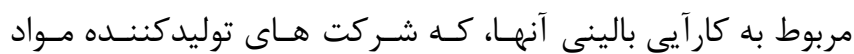

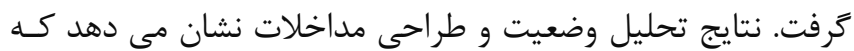
نقاط تمركز سياست توسعه يروبيوتيك ها و غذاهاى فراسـودمند در هر سه حوزه قانونى سياستى، فرهنگى رفتارى و ساختارى عمليـاتى ندي

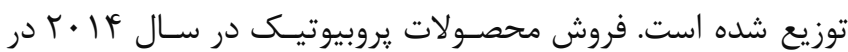

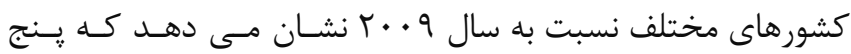

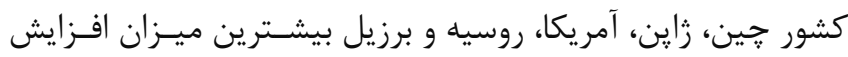


آيا به عنوان دارو، مكمل يا غذا برجسـب گَذارى شـود كـهـ در ايـن

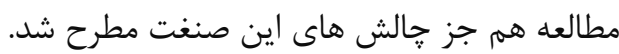

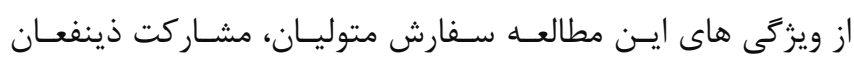

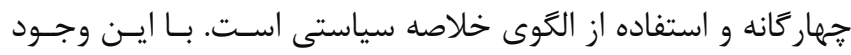
محدوديت هايى براى اين طراحى وجود داشـت كــه شـامل: شـكاف

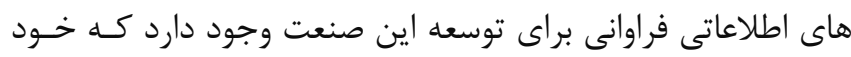

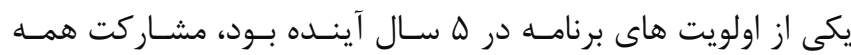
دانشگاهيان و مراكز تحقيقاتى مقدور نشد و مكاتبات با سازمان هاى ذينفع اصلى از جمله سازمان غذا و دارو به نتيجه نرسيد. با استفاده از داده هاى حاصل از مرور منابع موجود، نظرات ذات ذينفعان

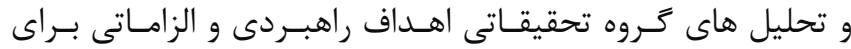

توسعه صنعت يروبيوتيك و غذاهاى فراسودمند يِيشنهاد مى شود.

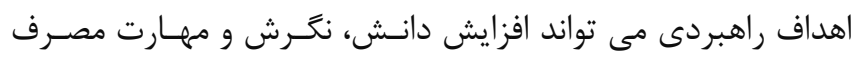

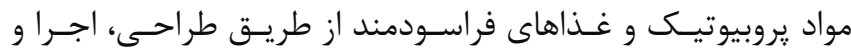
ارزشيابى يروزه بازاريابى اجتماعى مصرف محصـولات يروبيوتيـك و

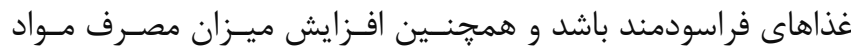
يروبيوتيك و غذاهاى فراسـودمند از طريـق تـدوين كتـاب سـرمايه

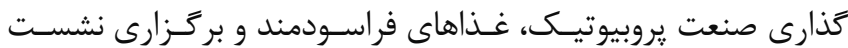
هاى ملى سرمايه گذارى و همجنين حمايت طلبى، استقرار مقررات و و استانداردهاى روزآمد صنايع يروبيوتيك و غـذاهاى فراسـودمند باشــد. براى توسعه صنعت يروبيوتيك لازم اسـت دانسش سياسـت گَذاران و و

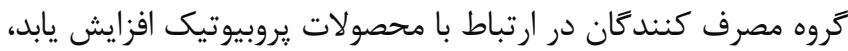
همزمان امنيت سرمايه كذارى در اين حوزه تامين شود و نظامى براى رصد توسعه اين صنعت و رفع مشكلات آن استقرار يابد.

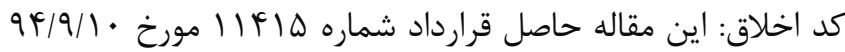
انجمن علمى يروبيوتيك و غذاهاى فراسودمند است كه براى تدوين

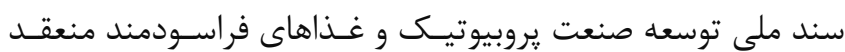
شده است.

تضاد منافع: مجرى و نويسند كان هيج تضـاد منــافعى در ارتبـاط بــاـ موضوع اين مقاله و كار مربوطه ندارند.

\section{سهم نويسند كان}

بهزاد دمارى: اجراى مطالعه، طراحسى :ـرزوهش و تحليـل داده ها

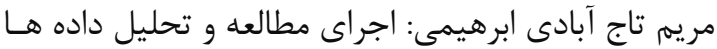

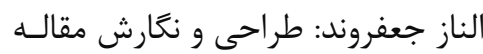

غذايى به دليل بودجه محدود تحقيق و توسعه و دانش فنى توانايى

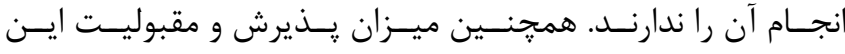

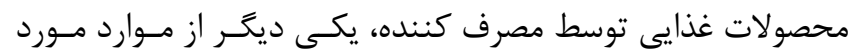
توجه جهت توسعه نوشيدنى هاى فراسودمند بيان شد كه بـا يافتـهـ هاى اين مطالعه همخوانى دارد.

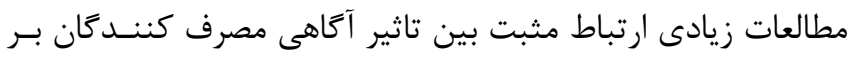

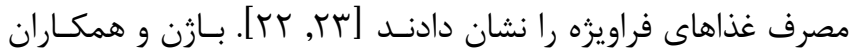

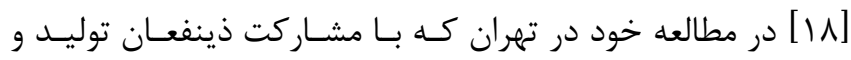
سلامت و همجنين مصرف كنندكان صورت كرفت، مهمترين موانسع

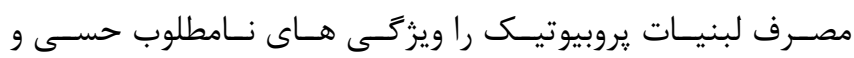
غير حسى، عدم دسترسى فيزيكى و اقتصـادى بــه محصـول، وجـود

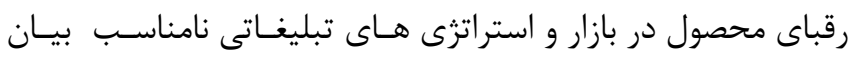

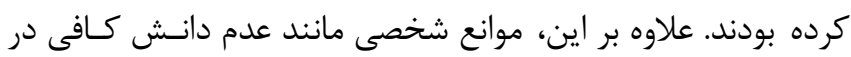

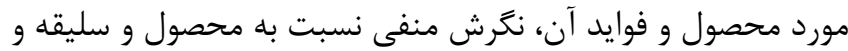
اولويت شخصى در انتخاب و مصرف آن دخيل بود كه با يافته هـاى نداى

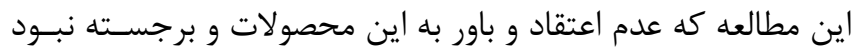

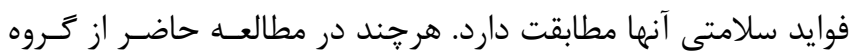

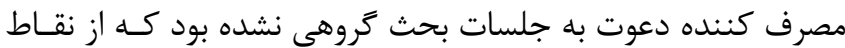

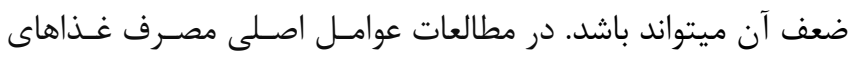

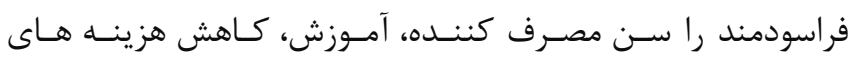

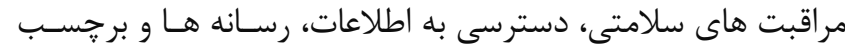

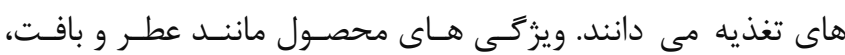

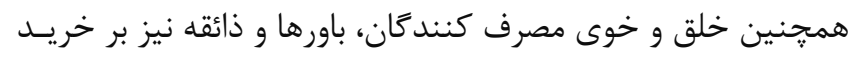

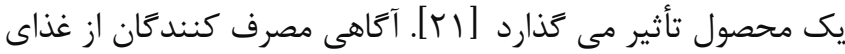

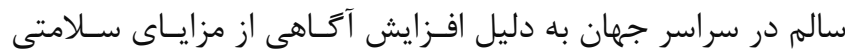

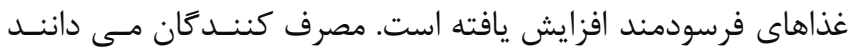

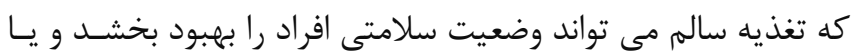

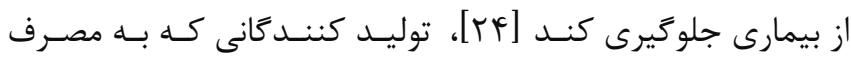

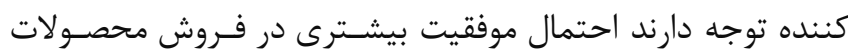

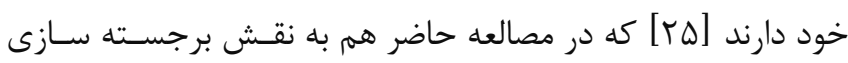

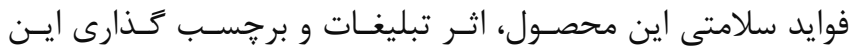
محصولات توسط ذينفعان اشاره شد.

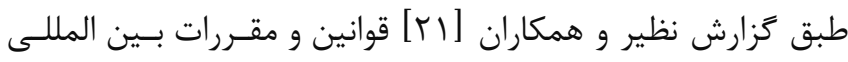

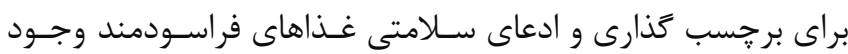
ندارد بنابراين، ابهام در برجسب زدن اين محصولات وجـود دارد كـهـ فئس 
ناظر و سياست گَذار كه در جلسات بحث گَروهـى متمركـز شـركت

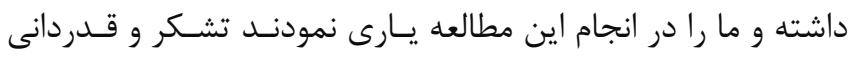

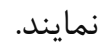

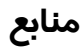

1. Azadnajafabad S, Mohammadi E, Aminorroaya A, Fattahi N, Rezaei S, Haghshenas R, et al. Non-communicable diseases' risk factors in Iran; a review of the present status and action plans. Journal of Diabetes and Metabolic Disorders 2021;22:1-9

2. Institute for Health Metrics and Evaluation (IHME). Global Health Data exchange (GHDx) 2019. Available on: http://ghdx.healthdata.org/gbd-resultstool [Accessed 21 Apr 2021]

3. Khosravi Shadmani F, Farzadfar F, Larijani B, Mirzaei M, Haghdoost AA. Trend and projection of mortality rate due to non-communicable diseases in Iran: A modeling study. PloS one 2019;14:e0211622.

4. Aminorroaya A, Fattahi N, Azadnajafabad S, Mohammadi E, Jamshidi K, Khalilabad MR, et al. Burden of non-communicable diseases in Iran: past, present, and future. Journal of Diabetes and Metabolic Disorders 2020;19:1-7

5. Low W-Y, Lee Y-K, Samy AL. Noncommunicable diseases in the Asia-Pacific region: Prevalence, risk factors and community-based prevention. International Journal of Occupational Medicine and Environmental Health 2015;28:20-6

6. Peykari N, Hashemi H, Dinarvand R, HajiAghajani M, Malekzadeh R, Sadrolsadat A, et al. National action plan for non-communicable diseases prevention and control in Iran; a response to emerging epidemic. Journal of Diabetes and Metabolic Disorders 2017;16:3

7. Di Daniele N. The Role of Preventive Nutrition in Chronic Non-Communicable Diseases. Nutrients 2019;11:1074

8. Noce A, Marrone G, Di Daniele F, Ottaviani E, Wilson Jones G, Bernini R, et al. Impact of Gut Microbiota Composition on Onset and Progression of Chronic Non-Communicable Diseases. Nutrients 2019;11:1073

9. Fuller R. Probiotics in man and animals. Journal of Applied Microbiology 1989;66:365-78

10. Food and Agriculture Organization, World Health Organization. Joint FAO/WHO Working Group Report on Drafting Guidelines for the Evaluation of Probiotics in Food, London, Ontario, Canada 2002:1:1-11

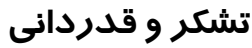

$$
\begin{aligned}
& \text { نويسندكان اين مقاله لازم مى دانند از تمامى شركت كنندكان اعـم }
\end{aligned}
$$

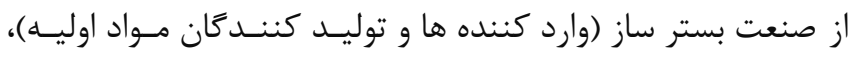

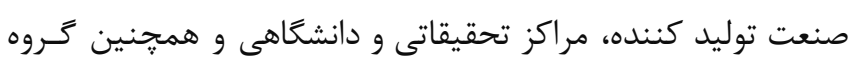

11. Sun-Waterhouse D. The development of fruit-based functional foods targeting the health and wellness market: a review. International Journal of Food Science and Technology 2011;46:899-920

12. Pandey KR, Naik SR, Vakil BV. Probiotics, prebiotics and synbiotics-a review. International Journal of Food Science \& Technology 2015;52:7577-87

13. Cho I, Blaser MJ. The human microbiome: at the interface of health and disease. Nature Reviews Genetics 2012;13:260-70

14. Dror T, Dickstein Y, Dubourg G, Paul M. Microbiota manipulation for weight change. Microbial Pathogenesis 2017;106:146-61

15. Razmpoosh E, Javadi M, Ejtahed HS, Mirmiran P. Probiotics as beneficial agents in the management of diabetes mellitus: a systematic review. Diabetes/Metabolism Research and Reviews 2016;32:143-68

16. Beserra BT, Fernandes R, do Rosario VA, Mocellin MC, Kuntz MG, Trindade EB. A systematic review and meta-analysis of the prebiotics and synbiotics effects on glycaemia, insulin concentrations and lipid parameters in adult patients with overweight or obesity. Clinical Nutrition 2015;34:845-58

17. Hibberd AA, Lyra A, Ouwehand AC, Rolny $\mathrm{P}$, Lindegren $\mathrm{H}$, Cedgard $\mathrm{L}$, et al. Intestinal microbiota is altered in patients with colon cancer and modified by probiotic intervention. BMJ Open Gastroenterology 2017;4:e00145

18. Bazhan $M$, Kalantari N, KeshavarzMohammadi N. Health-enhancing foods: barriers to consumers' choice in Iran. Health Promotion International. 2020; Avaialable on: https://doi.org/10.1093/heapro/daaa088 [Accessed Apr 2021].

19. Metchnikoff II. The prolongation of life: optimistic studies. $1^{\text {st }}$ EditionOutlook Verlag GmbH: Germany, 2004

20. Sanders ME. Development of consumer probiotics for the US market. British Journal of Nutrition 1998;80:213-8

21. Nazir M, Arif S, Khan RS, Nazir W, Khalid N, Maqsood S. Opportunities and Challenges for 
Functional and Medicinal Beverages: Current and Future Trends. Trends in Food Science and Technology 2019;88:518-26

22. Temesi A, Bacso A, Grunert KG, Lakner Z. Perceived correspondence of health effects as a new determinant influencing purchase intention for functional food. Nutrients 2019;11:740

23. Annunziata A, Vecchio R, Kraus A. Factors affecting parents' choices of functional foods targeted for children. International Journal of Consumer Studies 2016;40:527-35

24. Daliri EB-M, Lee BH. Current trends and future perspectives on functional foods and nutraceuticals. Beneficial microorganisms in food and nutraceuticals 2015;27:221-44

25. Sorenson D, Bogue J. Consumer-oriented development of functional beverages. Functional and Speciality Beverage Technology 2009;3:421-50 